\title{
A Case Study of Enterprise Cleaner Production Audit of Urban Garbage Disposal
}

\author{
Wei $\mathrm{Li}^{1, \mathrm{a}}$, Tingting Pan ${ }^{2, \mathrm{~b}}$, Zihao Zhou ${ }^{3, \mathrm{c}}$, Yaochun $\mathrm{Yu}^{4, \mathrm{~d}}$ and Haiyan Duan ${ }^{5, \mathrm{e}}$ \\ ${ }^{1}$ College of Environment and Resources, Jilin University, China \\ ${ }^{2}$ College of Environment and Resources, Jilin University, China \\ ${ }^{3}$ College of Environment and Resources, Jilin University, China \\ ${ }^{4}$ College of Environment and Resources, Jilin University, China \\ ${ }^{5}$ College of Environment and Resources, Jilin University, China \\ a173933065@qq.com, b1037199743@qq.com, c1120759122@qq.com, \\ d277765231@qq.com, eduanhy1980@jlu.edu.cn
}

\begin{abstract}
Keywords: cleaner production audit, urban garbage disposal, pollutants, economic benefit
Abstract. With the sustainable development of society and economy, people's living standard is experiencing a steady improvement, a lot of urban domestic garbage has become a social problem which contaminates the environment and influences our life. Reasonable and effective solutions are both actively looked for at home and abroad.In this article, we comprehensively discuss the current situation of cleaner production audit of urban garbage disposal both at home and abroad. By studying the instance of cleaner production audit of energy-saving domestic garbage comprehensive disposal project in Shuangyang district, Changchun in combination with related literature, we conclude the processes of enterprise cleaner production audit of urban garbage disposal and the merit and demerit of cleaner production audit. We reach the conclusion comprehensively: enterprise cleaner production audit of urban garbage disposal can effectively reduce energy consumption and pollutant emissions, and improve the economic benefits of enterprises.
\end{abstract}

\section{Background}

After the reform and opening-up, our country entered the period of rapid economic growth, the size and the number of cities expanded sharply, which made the problem of urban domestic garbage pollution becomes more and more prominent, and the management and control of it becomes one of the outstanding problems in the field of environmental protection. In addition to only a small number of urban domestic garbage in our country used to burn, compost or recycle, the remaining $70 \%$ of it is transported to a landfill for disposal. During the processes of storage, loading and unloading, tiling and compaction in the landfill, the garbage will produce pollution of stench inevitably due to the decomposition of organic matter. The degree of resource utilization of waste in our country is low, the recycling utilization rate of the solid waste was $69 \%$ and the recovery rate of iron blast furnace slag is $85 \%$, the secondary utilization rate of scrap metal resources is less than $5 \%$ in an annual total increase, while France has been more than 30\% and America has been 25\% 30\%.At present, the garbage disposal is mainly divided into land filling, composting and burning at home and abroad, Due to the different economic development level, the different habits and customs and natural geographical conditions, different countries and regions have big differences on the way of disposal, the vast majority of China's current domestic garbage is disposed with land filling or even simple landfill treatment.

Based on the above problems, we are required to dispose and audit the urban garbage from three aspects. Firstly, we should control the amount of municipal waste from the sources. Secondly, we ought to accelerate the urban garbage treatment technology innovation and enhance the harmlessness of municipal waste. Thirdly, increase the sorted collection and cyclic utilization of municipal waste. 


\section{Theoretical basis}

\section{the theoretical basis of cleaner production}

"Cleaner production means the continuous use of integrated prevention strategies of environmental protection in the production processes and products, in order to reduce the risk to humans and the environment. The connotation of cleaner production in essence is to adopt overall preventive environmental strategy in the production processes and products to reduce or eliminate their possible harm to humans and environment, at the same time to satisfy human needs, which is one of the best production models to maximize social and economic benefits ." Cleaner production is to seek to prevent and control pollution of air, water and soil, to reduce the waste of emissions, and to reduce the damage to human beings in the process of industrial production and product design, we can say cleaner production is the necessary plan of sustainable development. Cleaner production and circular economy are advanced thoughts of economic development and the economic development pattern, in addition, it is the inevitable way of the industry, regional sustainable development. Cleaner production is the basis of circular economy, it is the scientific method to make the reduction come true.

\section{program of cleaner production audit}

For enterprises,cleaner production audit can really reduce the cost,the consumption of materials and energy,improve the efficiency of the use of material and energy.For countries, it indeedly,contain the country's central task of the energy conservation and emissions reduction, it is the important measures to reduce greenhouse gas emission that china commits to the world .For local governments, it is the important way and approach to complete the task of energy conservation and emissions reduction.Common steps of cleaner production audit are inquisitional procedure,audit,production and selection of scheme, analysis of feasibility,program implementation and sustainable cleaner production.

\section{Case study}

\section{enterprise general situation}

The name of this project is that comprehensive utilization of garbage with energy conservation and environment protection in a waste plant in changchun shuangyang district, the construction unit is some technology Ltd in Jilin province,ShuAngyangbranch,construction site is located in the west side of the Shuangyangdistrict landfill.There are landfills in the east and north, road in the south,Woodland in the west,no environmentally sensitive areas within the scope of $900 \mathrm{~m}$ around.Scale of construction for daily capacity of household garbage is about 400t a day,and about $150000 t$ a year.After built up, it can deal with living garbage residents in Shuangyang district and other 6 townships of around, it can reach the degree that no residual and recycling, at the same time it can also deal with the garbage in existing Shuangyang district landfills (capacity of $170 \mathrm{t} / \mathrm{d}$ ), and change the past treatment in Shuangyang district to save land,reduce the damage of household garbage to the minimum, and achieve the environmental regulations stipulated by the state.

\section{analysis of present pollution situation}

Through the project analysis and field exploration and research, in operation period, the main poll ution sources that the project may take are as follows: 1.Garbage accessing, unloading and storage process, due to the decomposition of organic matter, the stench produced by them, not only endanger human health but also may cause secondary pollution.2.The gas produced from pyrolysis furnace and boiler,the dust from garbage sorting and the lampblack from the canteen can lead to harmful effects on air quality. 3.The production equipment and boiler blower can make noise and make effect on surrounding environment . 4.Emission of waste water washing vehicles, the workers' sewage and drainage of the boiler influence the environment of surface water.5.Ash of pyrolysis furnace ,the factory workers' living garbage and the inorganic matter which is sorted out have impact on the environment. 


\section{project evaluation}

\section{analysis of the cases of waste}

(a) Waste gas:Wastegas and stench pollution mainly comes from the garbage accessing, unloading stenchand flue gas of coal-fired boiler .(b) Waste water: Sewage is mainly composed of the waste water of factory equipment and the ground cleaning, living sewage and drainage of the boiler, the quantum of waste water is about $4000 \mathrm{~m} 3 /$ a, the main pollutants in the waste water treatment is COD, BOD5, SS, and ammonia nitrogen.(c)Noise :Noise mainly comes from the multi-function separator, loader, plate type feeder, pyrolysis furnace, and the boiler fan and water pump and so on, the noise level is between 80-95 dB (A).(d) Solid waste:The project is the urban garbage disposal project, the solid waste is urban domestic garbage, the main solid waste during project operation period is the pyrolysis furnace ash (9765.2 t/a), inorganic material (46030 t/a), the sorting dust collected by cloth bag(76.0 t/a), workers' living garbage( $35 \mathrm{t} / \mathrm{a})$ and waste activated carbon (9 t/a).

\section{production of scheme and analysis of feasibility}

Towards the emphasis of audit, analyze material balance and material and energy loss.In view of the audit emphasis, in the management of production, the control of production process, technology and equipment of production, making full use of energy and resources,put forward reasonable suggestions, make cleaner production plans and summarize them, as shown in table 1.

Table 1 Summary of cleaner production program

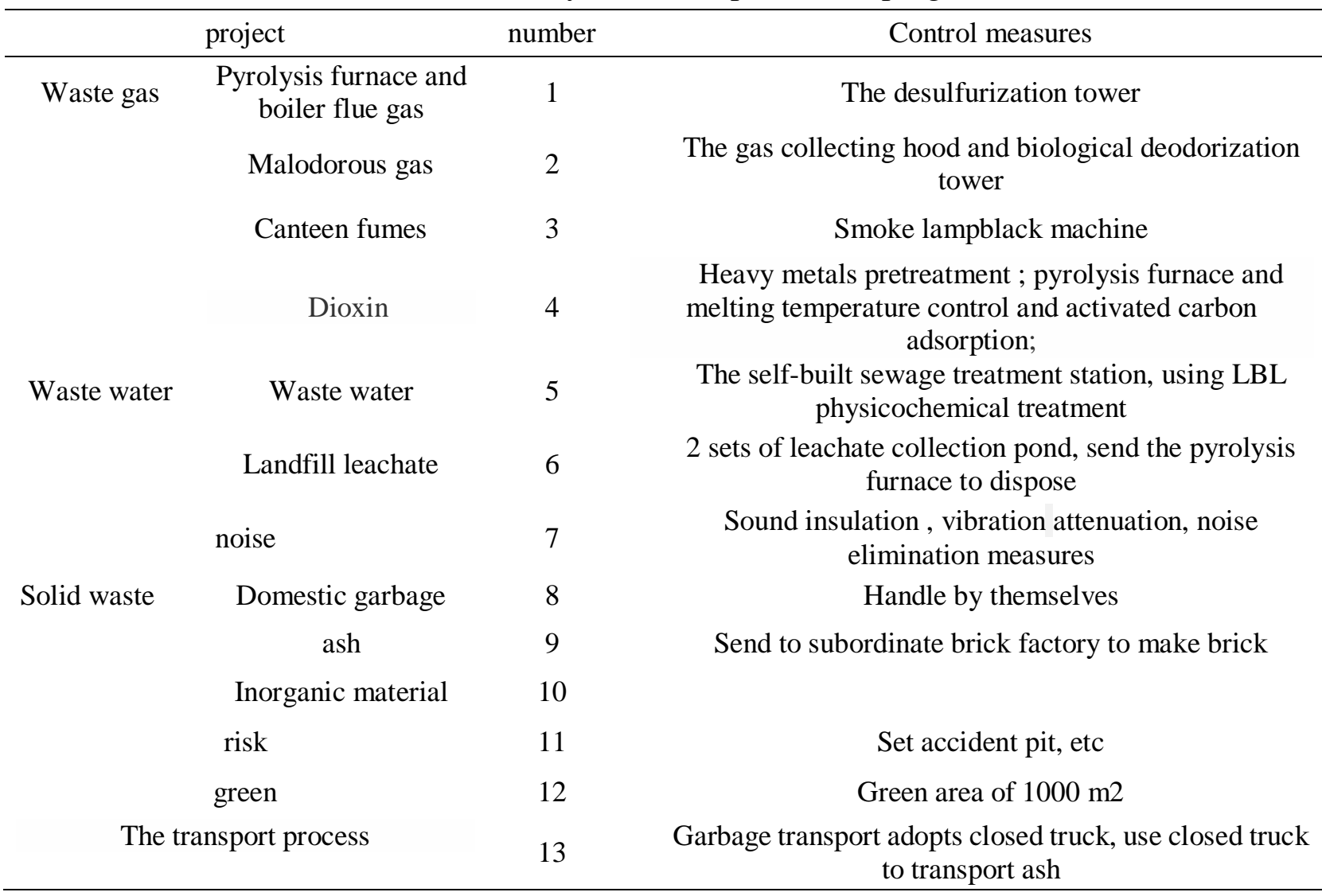

To select the project, we are mainly from four aspects to consider its feasibility. Namely: technical feasibility; environmental feasibility; economic feasibility and practicability.

The domestic garbage treatment technology in the project is the combination of pyrolysis, gasification,catalyst and carbon dioxide reduction. According to the principle of pyrolysis, gasification and carbon dioxide reduction, put the garbage into the reactor and heat, the garbage pyrolysis is at high temperature and hypoxia conditions.Tar, organic acid and water vapor in the mixed gas and part of waste carbon enter into the gas reaction device together and react again, making them convert into fuel gas with carbon monoxide, hydrogen, methane and so on. Another part of the waste carbon burns and produces heat to maintain the desired temperature during the pyrolysis reaction and make the new garbage continue to carbonate. The flue gas from the combustion of waste carbon enters into the mixed gas reaction device to generate the fuel gas which is mainly carbon 
monoxide and reuse it. The whole process cycles. During the process of garbage disposal, there is no emissions of waste gas, the only emission is about $8 \%$ harmless and inorganic residue. Pyrolysis process doesn't need external energy and has the advantages of small size, high degree of automation and convenient operation.

The waste leachate of the project is directly sent to pyrolysis furnance to pyrolyse, after the waste water is dealt with by standing sewage treatment plant to meet the grade I, it can be discharged into the Shuangwan river; The gas from pyrolysis furnace and boiler flue through spray, activated carbon adsorption treatment can meet the standard and be discharged, the dioxin emission after the prevention and treatment measures is almost zero; After collected through the gas-collecting hood, stench gas is disposed by the biological deodorization tower, sorting dust can meet standard and be discharged after processing a bag dust filter; Canteen lampblack is dealt with the smoke lampblack machine ; The project adopts low noise equipment, for the large noise equipment, we add damping cushion, muffler, acoustic and other noise reduction measures, to make it meet standard of noise at boundary of the factory, and have little impact on regional sound environment; The domestic garbage of the project is in disposal by ourselves, inorganic material, ash and dust are collected to send to subordinate brick factory to make brick, for the solid waste of this project, after taking the above measures, which has less impact on the environment, it won't bring secondary pollution problem.Ina word, this project's pollution after taking corresponding prevention measures will meet standard and can be discharged, and dioxin emissions are close to zero,it has little influence on the surrounding environment.

The project's total investment is RMB96.2056 million,the annual average businessin,come is RMB 16.5477 million, the internal financial rate of return is $11.15 \%$, the financial net present value is RMB 16.0230 million ,recovery period of investment is 7.5years(including construction period is 1 year), the project for the break even point is $54.45 \%$, it means the annual revenue reaches (RMB18.9075million ),so long as the design capacity reaches 54.58\%, RMB10.3160million, the ent erprise can break even,it seems that project operation has certain antirisk ability.

Therefore,this project's economic benefit is sigifican.Through the evaluation of technology, environment, economy and other aspects, it confirms that the above schemes are feasible, it can not only save energy and protect the environment, but also can obtain certain economic benefits. Therefore, we recommend all the above-mentioned solutions to put into effect.

\section{Conclusion and Enlightenment}

The main countermeasures and suggestions of this study are: (a) To speed up the pace of legislation and improve the legal system of cleaner production audit. The country should regulate from the angle of the law ,strengthen the management of enterprise cleaner production audit, pinpoint the authorities and establish a series of institutions for cleaner production audit advisory and service and the qualification certification system in the audit of cleaner production and set up legal restraints and penalty mechanisms related to cleaner production audit. (b)Develop the functions of the government and promote the advanced cleaner production audit technology. On the one hand, we should give full develop to the functions of the government and increase financial support. On the other hand, we need to increase scientific and technological innovation, promote clean production transformation and strengthen the cleaner production audit technology. (c) Strengthen publicity education and training. To strengthen publicity education and training,we should be a full range of education, both the education for the audit enterprises and the training for the audit institutions, it should also include the education and training for the whole society. At the same time,the publicity of cleaner production audit policy should be included, and the training for the clean production audit technology to achieve the improvement of both knowledge level and technical level.

\section{Acknowledgements}

The work was financially supported by National "Water pollution control and treatment technology major projects funds (2012ZX07202-009). 


\section{Reference}

[1]Xin Xiao-mu.2008.analysis of cleaner production of urban domestic garbage disposal.Journal of Meteorology and environment.

[2]Mu Ying.2000.current situation and development direction of urban garbage disposal in China. resource conservation and comprehensive utilization.

[3]Cai Bao-sen.2003.clean production of China's urban domestic garbage. energy and environmental protection.

[4] Hu Ying. 2001.the application of the idea of cleaner production in urban landfill.comprehensive utilization of resources in China.

[5] Liu Yang.2009. assessment of cleaner production audit based on resource and energy audit keypoints.environmental science and management. 